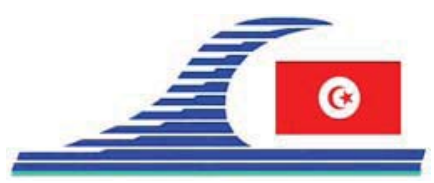

Conférence Méditerranéenne Côtière et Maritime

EDITION 1, HAMMAMET, TUNISIE (2009)

Coastal and Maritime Mediterranean Conference

Disponible en ligne - http://www.paralia.fr-Available online

\title{
Application of a GIS-based numerical modelling system at Marina di Rimini, Italy
}

\author{
Stuart STRIPLING ${ }^{1}$, Mario BERNERO ${ }^{1}$
}

1. HR Wallingford, Howbery Park, Wallingford, Oxfordshire, OX10 8BA, UK.

s.stripling@hrwallingford.co.uk;m.bernero@hrwallingford.co.uk

\begin{abstract}
:
Marina di Rimini is located on the western shore of the Northern Adriatic. The marina itself provides berthing for pleasure craft, and is accessed through a river channel which is trained several hundred metres into the sea. This layout is common along the Northern Adriatic coastline of Italy. On occasion, however, navigation along the river channel into the marina basin is thwarted by excess levels of wave disturbance.

It has been proposed to modify the layout of the river training walls so that greater protection from waves, and therefore safer navigation into the marina, is achieved. The objective of the study reported in this paper was to examine the potential impact on the nearby shoreline of modifying the layout of the river training walls.

Numerical models exploit our understanding of physical processes and it has become a standard requirement, in turn, to exploit numerical models when carrying out assessments of the effects of intervening at the coastline. The innovative method of assessment applied here at Marina di Rimini included the numerical modelling of wave propagation and sediment transport from within a GIS. This methodology not only enables straight-forward operability of the embedded models and the provision of readily assimilated model output, but it also takes the functionality of the GIS as a coastal management tool beyond a database and data-analysis system.
\end{abstract}

\section{Keywords:}

Coastal engineering - ICZM - Maritime hydraulics - Sediments - Maritime works Coastal environment - GIS - Numerical modelling

\section{Introduction}

Marina di Rimini, Regione Emilia Romagna, is located on the north-eastern Italian coastline (Figure 1). There has been a harbour here for centuries with records dating back to the $14^{\text {th }}$ Century. In those days, however, the harbour was about a kilometre further inland (ANTONIAZZI, 1976). A sudden, and then steady, rise in the population of the region resulting from the Roman occupation led to changes in land use such that forested areas were cleared to provide arable land for crops to feed the growing population. The result of the deforestation was that soils were eroded, and borne by the

$$
\text { DOI: } 10.5150 / \mathrm{cmcm} .2009 .016
$$


rivers to the coastline - which underwent centuries of advance. The harbour training walls at Rimini were gradually extended seaward in an effort to reduce sedimentation.

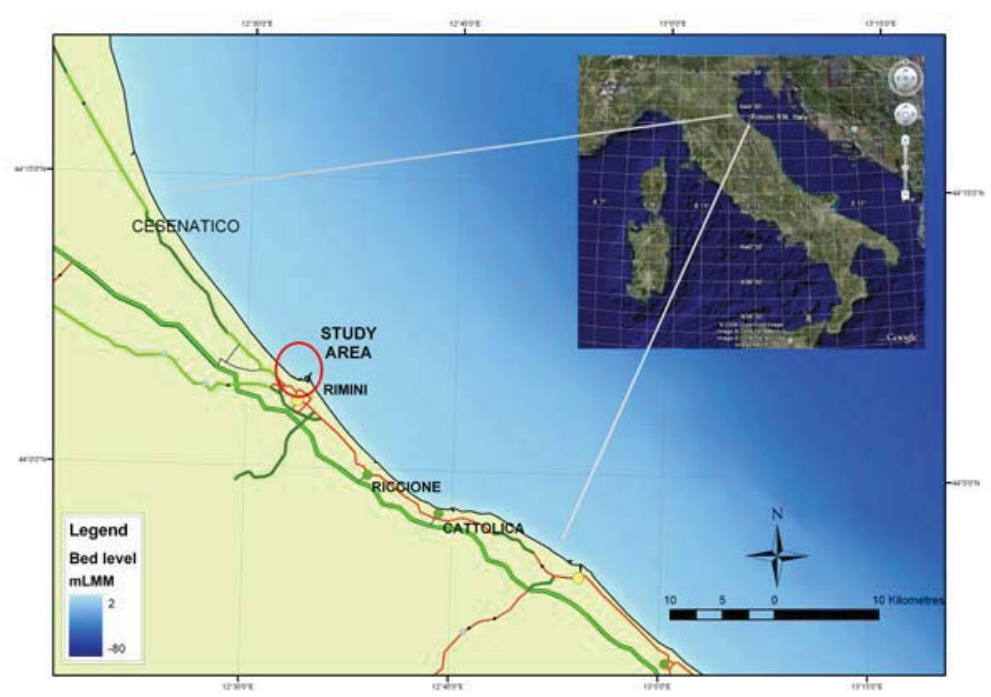

Figure 1. Location of Rimini.

More recently, reforestation together with the damming of rivers in the region and a lowering of the land resulting from the extraction of natural gas, have resulted in a reduced supply of sediments to the coast and an exacerbated recession of the shoreline, much of which is now protected by hard defences. Rimini is no exception, and here the shoreline immediately to the north of the marina is in a state of erosion and defended by breakwaters. These circumstances mean that any intervention along the coastline of Rimini has to be carefully assessed for adverse impacts before approval is granted.

Marina di Rimini is accessed from seaward through the relict mouth of the Fiume Marecchia (the Porto Canale), which is now diverted so that it emerges at the shoreline to the north of the marina. Navigation within Porto Canale is known to be hazardous under certain hydrodynamic forcing conditions, and proposals have been made to alter the configuration of the Molo di Levante (Figure 2) such that greater protection is afforded and navigation safer. An assessment of the potential effect on the sediment transport regime at the shoreline using GIS-embedded numerical models is the topic of the remainder of this short paper.

\section{Coastal sediment transport}

Sediment transport along the shoreline of the Adriatic Sea is dominated by longshore currents set up in response to the oblique angle of incidence of waves arriving in its shallow waters. At Rimini the nett direction of sediment transport is from south to north, and this is evidenced by the observed planshape of the shoreline, although north to south transport also occurs. 


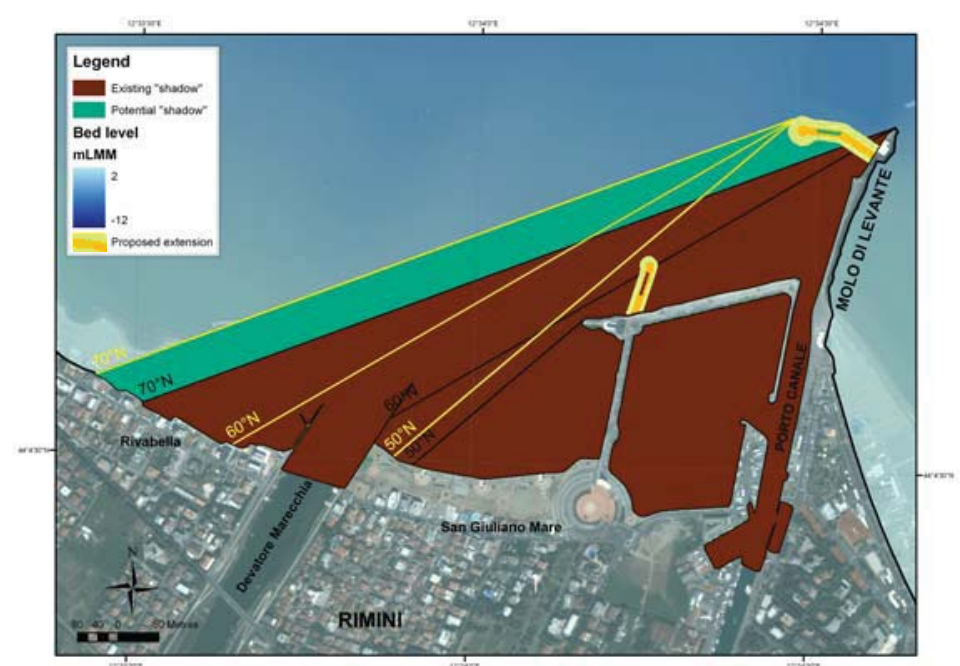

Figure 2. Proposed extension and shadow zones of Molo di Levante, Marina di Rimini.

Barriers to the longshore transport of beach material can influence the long-term evolution of the beach planshape. Where there is a dominant drift direction, the longterm shape of the beach will tend to be affected such that the updrift side of the barrier accretes beach material, while the downdrift side experiences a loss of beach material. The distance alongshore either side of the barrier over which the barrier affects the longterm beach planshape is strongly dependent upon the wave climate and the distance offshore that the barrier extends. Here at Rimini, it can be seen that the Molo di Levante has exerted such an influence, with the nett northwards transport of beach material being affected such that to the south there is a relatively wide beach, while to the north, coastal defence works have been introduced to counter the localised effects of the Molo.

\section{Numerical modelling of sediment transport}

Coastal sediment transport here at Rimini is driven by obliquely incident waves. A reasonable amount of data regarding waves in the Adriatic Sea is known. For example, the Ancona buoy - part of the Rete Ondametrica Nazionale - has recorded waves offshore from Ancona (80 km south-east of Rimini) from 1999 to 2006.

When examining the long-term behaviour of coastal sediments, it is good practice to obtain waves over as long a period as possible. Longer time-series of data is available from the Met Office European Wave Model, for example, where approximately 20 years of wave data can be obtained. For this study, offshore data was extracted from this model and calibrated against the measurements made by the RON Ancona buoy. The same calibration parameters were then used to tune wave data remote from the Ancona buoy location, but of relevance to the immediate locality of Rimini. With the use of wave hindcasting and wave transformation software, it was possible to construct approximately 20 years of wave climate data nearshore at Rimini. This nearshore wave 
data was used to drive numerical models of sediment transport along the coast. The innovation embeds these models such that they link and operate within a GIS.

The GIS coastal management tool (STRIPLING et al., 2007 and STRIPLING \& PANZERI, in press) consists, in part, of a back-tracking wave transformation model after LONGUET-HIGGINS (1957) dynamically linked to a process-rich sediment transport model (NAIRN \& SOUTHGATE, 1993 and SOUTHGATE \& NAIRN, 1993). Linkage of the wave and sediment transport models provides multiple nearshore wave climates, allowing the spatial variation of the wave climate to be captured giving localised representations of average annual longshore drift rates.

\section{Application of the GIS-based modelling system}

The proposed extension to the Molo di Levante extends the distance offshore that the barrier to longshore drift spans. The orientation of the extension is sympathetic to the bypassing of beach material, and it is therefore unlikely that there will be any noticeable change in sediment supply from the updrift to downdrift coastlines. However, the extension to the Molo may affect the propagation of waves to the north. The key issue addressed by the GIS-based modelling system, therefore, is to establish how far northwards the proposed Molo extension might be expected to be noticeable and to what extent the potential longshore transport of beach material is affected.

Analysis has shown that waves along the shoreline incident at less than about $50^{\circ} \mathrm{N}$ are unlikely to be affected by the proposed extensions, and Figure 2 shows the shadows cast by the extension on waves more obliquely incident. It can be seen that the shelter afforded by the Molo di Levante does not extend much further north than the Deviatore Marecchia even once it has been extended. It is evident that the beach of San Giuliano Mare is likely to be most strongly affected by extension of the marina infrastructure in terms of the direct shelter afforded by the structures, and separate analysis (not reported here) was performed for this beach.

Figure 3 shows how this translates into an impact on the cross-shore distribution and bulk sediment transport rates along the frontage (in $\mathrm{m}^{3} / \mathrm{yr}$ ) as determined by the numerical modelling element of the GIS system. It can be seen that although the extension to the Molo di Levante affects the longshore transport of beach material, the magnitude of this impact is only significant along the beach at San Giuliano Mare. The percentage change in average annual drift rates further north are seen to be of the order of (or less than) 1\% along the majority of the frontage away from San Giuliano Mare. Changes of such magnitude are considered to be indistinguishable from "natural" variations in numerical simulations, and of even less significance when compared to the likely annual variation in actual longshore sediment transport rates. 


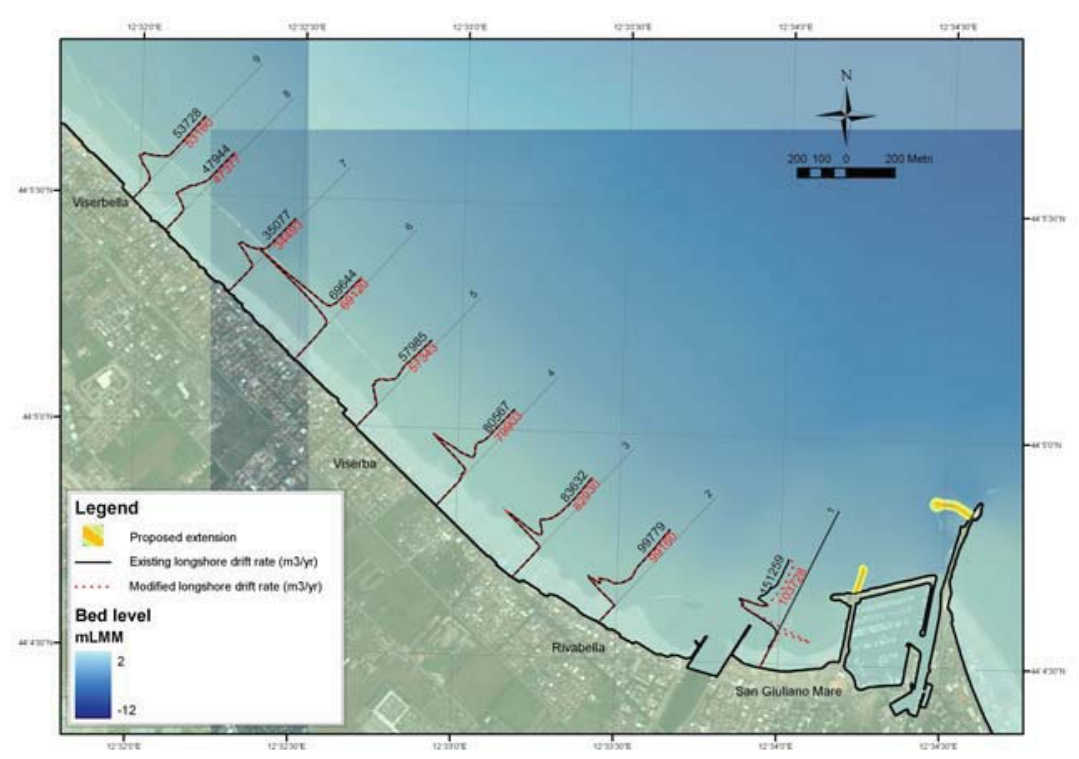

Figure 3. Impact of proposed extension on potential longshore transport, Marina di Rimini.

\section{Conclusions}

A series of GIS-based numerical models designed to examine the possible behaviour of littoral sediments in the vicinity of Marina di Rimini have been applied such that differences in wave propagation patterns and sediment transport behaviour in the event that the molo extension implemented can be ascertained. The main advantage of this approach is that it negates the need to apply more complex and costly morphodynamic numerical models.

The main conclusions of the study suggest that wave propagation patterns will alter marginally along the shoreline to the north of the Marina di Rimini and long-term average potential alongshore sediment transport rates are only affected to any significant degree along the pocket beach at San Giuliano Mare where the localised northward drift rates are thought to be reduced by up to about 30\%. Further north, the effect on the sediment transport rate is of the order of a $1 \%$ reduction in average annual drift rates. Such a reduction will not be noticeable, and is not expected to have any adverse impact.

\section{Acknowledgements}

The Authors are also grateful to Ing. Massimo Totti of "Comune di Rimini" and Ing. Mentino Preti “ARPA, Regione Emilia Romagna” with whose contributions the project reached environmental impact assessment approval on schedule. 
Meilleures pratiques environnementales en ingénierie côtière et maritime

\section{References}

ANTONIAZZI A. (1976). L'erosione marina nel litorale tra Cervia e Pesaro. Castrocaro Terme, Italia, $161 \mathrm{p}$.

LONGUET-HIGGINS M.S. (1957). On the transformation of a continuous spectrum by refraction. Proc. Camb. Phil. Soc. 53(1), pp 226-229.

NAIRN R.L., SSOUTHGATE H.N. (1993). Deterministic profile modelling of nearshore processes. Part 2. Sediment transport and beach profile development. Coastal Engineering, 19, pp 57-96.

SOUTHGATE H. N., NAIRN R. L. (1993). Deterministic profile modelling of nearshore processes. Part 1. Waves and currents. Coastal Engineering, 19, pp 27-56.

STRIPLING S., PANZERI M., KEMP J., BRAMPTON A. (2007). Broad-scale morphodynamic shoreline modelling within a standalone GIS coastal management tool: GTI-SEAMaT. Proceedings Int. Conf. Coastal Management, Institute of Civil Engineers, Cardiff, Oct.31-Nov.1 2007, pp 119-129.

STRIPLING S., PANZERI M. (in press). Modelling regional shoreline evolution to enhance flood-risk assessment. Accepted for publication (10/03/2009) by ICE Journal Maritime Engineering. 